\title{
Lukasz Pigoński, Polityka zachodnia cesarza Marcjana (450-457) i Leona I (457-474), Byzantina Lodzienasia 29, Lódź 2019, Wydawnictwo Uniwersytetu Lódzkiego, ss. 223 + VII
}

We wstępie do swej pracy autor zamieścił krótkie naukowe curriculum vitae, w którym zaznaczył, że napisał ,pracę magisterską u prof. Mirosława J. Leszki, która stała się fundamentem tejże książki" (s. 3). Niniejsza publikacja jest zatem swego rodzaju dowodem na duży potencjał intelektualny autora, ponieważ rzadko zdarza się, aby na postawie pracy magisterskiej powstała rozprawa warta publikacji w dobrej serii wydawniczej. Już więc choćby z tego powodu warto przyjrzeć się bliżej dokonaniu pana Łukasza Pigońskiego.

Publikacja ta liczy w sumie 230 stron. Jej pierwszym elementem jest spis treści (s. V-VII), po którym zamieszczono krótki, bo tylko czterostronicowy wstęp (s. 1-4) zaopatrzony w 2 przypisy podtekstowe, co daje 0,500 przypisu na stronę (dalej: przyp./s.). Ponieważ zaś cała praca liczy 691 przypisów, zatem owe dwa przypisy to $0,289 \%$ wszystkich not. Rdzeń rozprawy stanowi sześć rozdziałów. Pierwszy z nich obejmuje 15 stron (s. 5-19) i posiada 63 przypisy (= 4,200 przyp./s.; 3,117\% wszystkich przyp.). Rozdział drugi (s. 21-49) to 29 stron i 105 przypisów (=3,620 przyp./s.; 15,195\% przyp.). Trzeci z kolei rozdział (s. 51-112) liczy aż 62 strony tekstu, które opatrzono 257 przypisami (=4,145 przyp./s.; 37,192\% przyp.). Wreszcie na ostatni, czwarty rozdział (s. 113-176) składają się 64 strony, które dopełnia aparat naukowy złożony również z 257 przypisów (= 4,015 przyp./s.; 37,192\% przyp.). Tę zasadniczą część pracy domyka pięciostronicowe zakończenie (s. 177-181), do którego dołączono jeszcze siedem przypisów (=1,400 przyp./s.; 1,013\% wszystkich not). Kolejnym elementem jest wykaz skrótów (s. 183-184) zawierający 38 abrewiacji. Wykaz ten poprzedza bibliografię (s. 185-199). Następnym segmentem rozprawy jest „Summary - Western Policy of Emperors Marcian (450-457) and Leo I (457-474)", które to résumé obejmuje cztery strony (s. 201-204). Po anglojęzycznym streszczeniu umieszczono „Indeks osób” (s. 205-211) oraz „Indeks nazw geograficznych i etnicznych” (s. 212-214). Po indek- 
sach znajduje się polskojęzyczny abstrakt wraz ze słowami kluczowymi (s. 215), a po nim abstrakt w języku angielskim oraz Keywords (s. 216). Całość zamyka wykaz prac opublikowanych dotąd w bizantynistycznej serii wydawanej przez Uniwersytet Łódzki - „Byzantina Lodziensia 1997-2019" (s. 217-223).

Wspomniana wyżej bibliografia rozprawy liczy 15 stron. Została ona podzielona na źródła (s. 185-189), których jest 35, i opracowania (s. 189-199) w liczbie 203 pozycji w sześciu językach: 103 po angielsku (=50,738\%), $50 \mathrm{w}$ języku polskim $(=24,630 \%), 40 \mathrm{w}$ języku niemieckim $(=19,704 \%), 8$ po francusku $(=3,940 \%), 1$ po hiszpańsku $(=0,492 \%)$ oraz jedna publikacja $\mathrm{w}$ języku rosyjskim $(=0,492 \%)$. W powyższym zestawieniu uderza wysoki udział publikacji w języku polskim, co wydaje się dobrze świadczyć o dynamice rozwoju rodzimej bizantynistyki, która ma coraz więcej do powiedzenia w zakresie m.in. analizowanej przez autora epoki w dziejach Bizancjum.

W pierwszym rozdziale, mającym charakter wprowadzenia a noszącym tytuł „Podstawe źródłowa do badań nad polityką zachodnią Marcjana i Leona I", autor charakteryzuje zachowaną spuściznę historyków późnego antyku, których dzieła posłużyły mu za bazę do przedstawienia zagadnienia sformułowanego w temacie rozprawy. Najważniejszym źródłem była niezachowana w całości Historia Pryskosa z Panion. Następnie Ł. Pigoński odwołuje się do autorów wschodnich, którzy z tego dzieła korzystali, czyli do niezachowanej Kroniki Eustacjusza z Epifanei, ponieważ „to przypuszczalnie za jej pośrednictwem wielu późniejszych autorów zawarło w swych dziełach relację Pryskosa" (s. 9), do odpowiednich fragmentów Historii wojen Prokopiusza z Cezarei, do Historii Kościoła Ewagriusza Scholastyka, do Chronografii Jana Malalasa, do zachowanej fragmentarycznie pracy Jana Antiocheńskiego, do Chronografii Teofanesa Wyznawcy, do zachowanej w dwóch streszczeniach Historii Kandyda oraz do żywotu Leona Słupnika. Spośród niezależnych od Pryskosa źródeł powstałych na Zachodzie natomiast Ł. Pigoński wymienia Kronikę Hydacjusza, Epitoma chronicon Prospera z Akwitanii, spuściznę Sydoniusza Apolinarego, Getica i Romana Jordanesa, Kronike Marcellina Komesa, Historię rzymska Pawła Diakona, tzw. Theodoriciana oraz Dzieje prześladowań Kościoła w Afryce Wiktora z Wity. Jako źródła pomocnicze autor wymienia De magistratibus Jana Lidyjczyka, Historię Malchosa z Filadelfii, Notitia Dignitatum i Epitoma rei militaris Wegecjusza. W zakończeniu swych źródłoznawczych rozważań podkreśla słusznie, że mimo pozornie dość obszernej bazy źródłowej wiele rzeczonych przekazów „traktuje jedynie w wąskich aspektach” 
(s. 19) kwestie podjęte w niniejszej publikacji, a „część zachowała się tylko we fragmentach, a inne przedstawiają narrację z perspektywy epoki odległej opisanym wydarzeniom" (s. 19). W konsekwencji autor sugeruje, że analizowane przezeń zagadnienia można w dużej mierze odtwarzać tylko hipotetycznie w oparciu o skromne dane źródłowe i intuicję badawczą. To zaś podpowiada czytelnikowi, że Ł. Pigoński podjął się rzeczy trudnej i ryzykownej, szczególnie dla młodego badacza dziejów antycznych.

Rozdział drugi, „Zarys funkcjonowania późnorzymskiej polityki zewnętrznej”, należy również do bloku wprowadzającego we właściwy tok analiz i ma za zadanie przedstawienie wybranych zagadnień rzeczonej polityki, koniecznych do właściwego zrozumienia dalszego toku wywodów. $\mathrm{Z}$ tego względu w kolejnych paragrafach, których dosłowne tytuły przytoczono niżej, zostały poruszone takie kwestie, jak: (1) cesarz i jego otoczenie (s. 22-24), (2) władza centralna a problemy pogranicza (s. 24-28), (3) dyplomacja (s. 28-33), (4) armia rzymska (s. 34-37), (5) foederati i bucellarii (s. 37-39), (6) flota (s. 39-40), (7) siły barbarzyńców (s. 41-42), (8) Hunowie (s. 42-45), (9) Wandalowie (s. 46-49). Rozdział ten pokazuje dobrze fakt, że zachodnia polityka cesarzy bizantyńskich była niejako rozdarta między dwoma biegunami, czyli między stosunkami z Hunami i Wandalami. To te dwa tak odległe geograficznie barbarzyńskie bieguny zła sprawiały, że zachodnia polityka bizantyńska oraz wysiłek militarny cesarstwa musiały „stać w rozkroku”. Jeśli dodać do tego stosunki z Persją, stosunki polityczne i religijne z Rzymem oraz kwestie związane $\mathrm{z}$ funkcjonowaniem dworu konstantynopolitańskiego, gdzie pierwsze skrzypce grał alański wódz, arianin Aspar, wówczas uzyskuje się skomplikowany schemat geopolityczny, w jakim przyszło funkcjonować zarówno Marcjanowi, jak i Leonowi I. Rozdział ten został logicznie skonstruowany i dobrze spełnia funkcję zarysu skomplikowanego tła epoki.

Rozdział trzeci, „Między izolacją a stabilizacją. Polityka zachodnia Marcjana", składa się z dwunastu paragrafów, których tytuły dobrze oddają treściową zawartość tego segmentu książki: (1) polityka zachodnia Teodozjusza II (s. 52-57), (2) zagrożenie ze strony Hunów (s. 57-66), (3) bilans rządów Teodozjusza II (s. 66-67), (4) objęcie tronu przez Marcjana (s. 67-68), (5) kariera Marcjana (s. 68-70), (6) Aspar i jego kariera (s. 70-72), (7) Marcjan jako kandydat do tronu (s. 72-78), (8) Marcjan wobec zagrożenia ze strony Hunów (s. 78-83), (9) wyprawa Attyli na Italię (s. 83-99), (10) polityka zachodnia Marcjana w latach 453-457 (s. 99-108), (11) Marcjan a Marcellin z Dalmacji (s. 108-110), (12) bilans rządów Marcjana (s. 111-112). Rozdział ten można traktować na gruncie polskiej 
literatury przedmiotu jako swego rodzaju zwięzłą monografię na temat cesarza Marcjana. Autor książki wykazał się tutaj znaczną samodzielnością sądów oraz logiczną spójnością przeprowadzonych przez siebie analiz. Do tego należy dodać klarowność wywodu, który bardzo ułatwia czytelnikowi uchwycenie istoty rozważań autora i zachęca do lektury.

Podobnymi cechami odznacza się rozdział czwarty, „Próba przywrócenia jedności imperium. Polityka zachodnia cesarza Leona I”. Ten segment pracy został podzielony na piętnaście paragrafów o następujących tytułach: (1) objęcie władzy przez Leona (s. 113-116), (2) Leon i Majorian (s. 116-118), (3) rządy Majoriana (s. 118-122), (4) relacje cesarstwa z Ostrogotami (s. 122-127), (5) ambicje dynastyczne Leona (s. 127-129), (6) odwilż w relacjach rzymsko-wandalskich (s. 129-132), (7) konflikt Leona z Asparem (s. 132-134), (8) konflikt Gotów ze Skirami. Bałkany w latach sześćdziesiątych (s. 134-142), (9) relacje z Hunami za panowania Leona (s. 142-148), (10) interwencja Leona na Zachodzie (s. 149-152), (11) wyprawa przeciw Wandalom (s. 152-157), (12) Bazyliskos i przyczyny klęski przy Cap Bon (s. 157-163), (13) następstwa klęski (s. 163-167), (14) ostatnie lata panowania Leona (s. 167-173), (15) bilans rządów Leona (s. 173-176). I w tym przypadku można na gruncie polskim traktować niniejszy rozdział jako bardzo syntetyczną biografię Leona I.

Wnioski końcowe znajdują się w trzech, wspomnianych już wyżej elementach rozprawy: w zakończeniu, w anglojęzycznym streszczeniu oraz w dwóch abstraktach (polsko- i angielskojęzycznym). W ten sposób czytelnik ma okazję niejako trzy razy powrócić do najistotniejszych tez książki Ł. Pigońskiego, co można traktować jako dobry zabieg mnemotechniczny.

Praca niniejsza posiada stosunkowo niewiele błędów językowych. Poniższy wykaz nie pretenduje do kompletności, prezentuje natomiast te uchybienia, które udało się wychwycić niżej podpisanemu:

\begin{tabular}{|c|c|c|}
\hline lokalizacja & jest & powinno być \\
\hline s. 8, lin. 4 od góry & i antypatie i dawał & i antypatie, i dawał \\
\hline $\begin{array}{c}\text { s. 11, przyp. 28, lin. 2-3 od } \\
\text { góry }\end{array}$ & ed. C. Thurn, M. Meier & $\begin{array}{c}\text { übers. von H. Thurn und M. } \\
\text { Meier }\end{array}$ \\
\hline s. 12, przyp. 34, lin. 2 od góry & konzeption & Konzeption \\
\hline s. 12, lin. 4 od góry & Isauriers & Isaurier \\
\hline s. 12, lin. 5 od góry & Jahrhundert & Jahrhunderts \\
\hline s. 12, lin. 5 od góry & ed. & hrsg.von \\
\hline s. 13, przyp. 40, lin. 1 od góry & J.M. Kotter & J.-M. Kötter \\
\hline
\end{tabular}




\begin{tabular}{|c|c|c|}
\hline s. 13 , lin. $1-2$ od góry & $\begin{array}{c}\text { [złe podział na sylaby] } \\
\text { Lat-erculus }\end{array}$ & La-terculus \\
\hline s. 13, lin. 2 od góry & J.M. Kotter, M. Becker & M. Becker/J.-M. Kötter \\
\hline s. 13, przyp. 41 , lin 1 od góry & J.M. Kotter & J.-M. Kötter \\
\hline s. 15, przyp. 45, lin. 1 od góry & D. Alvarez Jimenez & D. Álvarez Jiménez \\
\hline s. 21 , przyp. 1 , lin. 2 od góry & Cairns & Leeds \\
\hline s. 26 , lin. 11 od dołu & cursus publicum & cursus publicus \\
\hline s. 30, lin. 8 od góry & Plinta & Plinta, \\
\hline s. 30, lin. 7 od dołu & $\begin{array}{c}\text { znajomości, z Maksymi- } \\
\text { nem }\end{array}$ & znajomości z Maksyminem \\
\hline s. 34 , przyp. 43 , lin. 2 od góry & Bohec & Le Bohec \\
\hline s. 34, przyp. 43 , lin. 2 od góry & L'Armee Romaine & L'Armée romaine \\
\hline s. 36 , przyp. 53 , lin. 4 od góry & Archeology & Archaeology \\
\hline s. 36 , lin. 2 od dołu & $\begin{array}{c}\text { [brak części opisu bibli- } \\
\text { ograficznego] Perspec- } \\
\text { tive, ed. }\end{array}$ & $\begin{array}{c}\text { Perspective, Materials of } \\
\text { the International Confer- } \\
\text { ence, 2-5 September 1998, } \\
\text { ed. }\end{array}$ \\
\hline s. 37 , przyp. 60 , lin. 1 od góry & Die Bucellariertum & Das Bucellariertum \\
\hline s. 39, przyp. 65 , lin. 1 od góry & Redde & Reddé \\
\hline s. 39, lin. 2 od góry & Roma & Rome-Paris \\
\hline s. 49 , przyp. 102 , lin. 1 od góry & Babaren & Barbaren \\
\hline s. 56 , przyp. 27 , lin. 1 od góry & Wandalos & Vandalos \\
\hline s. 56, lin. 2 od góry & movet, Ariobindo & movet Ariobindo \\
\hline s. 56, lin. 3 od góry & fuer & fuere \\
\hline s. 62, przyp. 60 , lin. 2 od dołu & dużo, bardziej & dużo bardziej \\
\hline s. 64 , przyp. 71 , lin. 2 od dołu & $\begin{array}{l}\text { im ausgehenden. West- } \\
\text { römischen }\end{array}$ & $\begin{array}{c}\text { im ausgehenden Weströmis- } \\
\text { chen }\end{array}$ \\
\hline $\begin{array}{l}\text { s. } 68, \text { przyp. } 93, \text { lin. } 1-2 \text { od } \\
\text { góry }\end{array}$ & funkcję, zapewne & funkcję. Zapewne \\
\hline s. 84 , przyp. 156 , lin. 4 od góry & J.M. Kotter & J.-M. Kötter \\
\hline s. 84, lin. 2 od dołu & J.M. Kotter, M. Becker & M. Becker/J.-M. Kötter \\
\hline s. 84, przyp. 158, lin. 2 od dołu & J.M. Kotter & J.-M. Kötter \\
\hline s. 93, lin. 10-11 & trudno trudno & trudno \\
\hline s. 122 , lin. 6 od dołu & Windobona & Vindoboną \\
\hline s. 130 , lin. 16 od góry & Leona $^{70}$. & Leona $^{70}$. \\
\hline $\begin{array}{l}\text { s. 141, przyp. 112, lin. } 2 \text { od } \\
\text { dołu }\end{array}$ & tagmaton en ton illyrois & $\begin{array}{c}\text { [zwykle autor cytuje teksty } \\
\text { greckie w oryginale] }\end{array}$ \\
\hline $\begin{array}{l}\text { s. } 159, \text { przyp. } 192, \text { lin. } 2 \text { od } \\
\text { góry }\end{array}$ & nachristlichen & nachchristlichen \\
\hline s. 159 , lin. 2-3 od góry & Jahrhundert & Jahrhunderts \\
\hline s. 159, lin. 3 od góry & ed. & hrsg. Von \\
\hline s. 165, lin. $7-8$ od góry & Teofanes, Izauryjczyk & Teofanes, gdy Izauryjczyk \\
\hline s. 165 , lin. 4 od dołu & byl & został \\
\hline
\end{tabular}




\begin{tabular}{|c|c|c|}
\hline s. 185 , lin. 5-6 od dołu & Armenie (2x) & Arménie (2x) \\
\hline s. 188 , lin. 8-9 od góry & J.M. Kotter, M. Becker & M. Becker/J.-M. Kötter \\
\hline s. 189, lin. 1 od dołu & Cairns & Leeds \\
\hline s. 190 , lin. 6 od góry & Bohec & $\begin{array}{c}\text { Le Bohec [trzeba też } \\
\text { zmienić miejsce tej pozycji } \\
\text { w bibliografii] }\end{array}$ \\
\hline s. 190, lin. 8 od góry & des Römisches Reiches & des römischen Reiches \\
\hline s. 190 , lin. 9 od góry & $\begin{array}{l}\text { nachristlichen Jahrhun- } \\
\text { dert }\end{array}$ & $\begin{array}{l}\text { nachchristlichen Jahrhun- } \\
\text { derts }\end{array}$ \\
\hline s. 190, lin. 10 od góry & ed. & hrsg. von \\
\hline s. 190, lin. 13 od góry & konzeption & Konzeption \\
\hline s. 190 , lin, 14 od góry & $\begin{array}{l}\text { nachristlichen Jahrhun- } \\
\text { dert }\end{array}$ & $\begin{array}{l}\text { nachchristlichen Jahrhun- } \\
\text { derts }\end{array}$ \\
\hline s. 190, lin, 14 od góry & ed. & hrsg. Von \\
\hline s. 190 , lin. 20 od góry & $\begin{array}{l}\text { nachristlichen Jahrhun- } \\
\text { dert }\end{array}$ & $\begin{array}{l}\text { nachchristlichen Jahrhun- } \\
\text { derts }\end{array}$ \\
\hline s. 190, lin. 20 od góry & ed. & hrsg. Von \\
\hline s. 191, lin. 3 od góry & Babaren & Barbaren \\
\hline s. 192, lin. 1 od góry & Die Bucellariertum & Das Bucellariertum \\
\hline s. 193, lin. 16 od dołu & Jimenez & Jiménez \\
\hline s. 194, lin. 16 od góry & J.M. Kotter & J.-M. Kötter \\
\hline s. 194, lin. 17 od góry & J.M. Kotter, M. Becker & M. Becker/J.-M. Kötter \\
\hline s. 195, lin. 3 od dołu & Isauriers & Isaurier \\
\hline s. 195, lin. 2 od dołu & $\begin{array}{c}\text { nachristlichen Jahrhun- } \\
\text { dert }\end{array}$ & $\begin{array}{l}\text { nachchristlichen Jahrhun- } \\
\text { derts } \\
\end{array}$ \\
\hline s. 195, lin. 2 od dołu & ed. & hrsg. Von \\
\hline s. 196 , lin. 2 od góry & ed. C. Thurn, M. Meier & $\begin{array}{l}\text { übers. von H. Thurn und M. } \\
\text { Meier }\end{array}$ \\
\hline s. 196 , lin. 14 od góry & Archeology & Archaeology \\
\hline s. 196 , lin. 15 od góry & $\begin{array}{c}\text { [brak części opisu bibli- } \\
\text { ograficznego] Perspec- } \\
\text { tive, ed. }\end{array}$ & $\begin{array}{c}\text { Perspective, Materials of } \\
\text { the International Confer- } \\
\text { ence, 2-5 September 1998, } \\
\text { ed. }\end{array}$ \\
\hline s. 197, lin. 5 od góry & Redde & Reddé \\
\hline s. 197, lin. 6 od góry & Roma & Rome-Paris \\
\hline s. 197, lin. 10 od dołu & $\begin{array}{l}\text { im ausgehenden. We- } \\
\text { strömischen }\end{array}$ & $\begin{array}{l}\text { im ausgehenden Weströmi- } \\
\text { schen }\end{array}$ \\
\hline s. 198 , lin. $11-12$ od dołu & $\begin{array}{c}\text { nachristlichen Jahrhun- } \\
\text { dert }\end{array}$ & $\begin{array}{l}\text { nachchristlichen Jahrhun- } \\
\text { derts }\end{array}$ \\
\hline s. 198, lin. 11 od dołu & ed. & hrsg. von \\
\hline
\end{tabular}

Prócz powyższej erraty można wskazać również inne braki. W bibliografii bowiem autor prawie zupełnie pomija serie wydawnicze. Oto kilka 
przykładów: publikacja R.C. Blockleya (East Roman Foreign Policy) ukazała się jako pozycja $30 \mathrm{w}$ ramach serii Arca (s. 189); praca Y. Le Boheca (L'Armée romaine) to rozprawa $11 \mathrm{w}$ serii Antiquité. Synthèses (s. 190); opracowanie Griechische Profanhistoriker wyszło jako publikacja 228 serii Historia/Einzelschriften (s. 190, 195 i 198); książka K. Felda (Barbarische Bürger) wyszła z kolei jako ósma w serii Millennium-Studien (s. 192); w tej samej serii (nr 57) ukazała się dysertacja R. Kosińskiego (Holiness and Power) - s. 194; praca P. MacGeorge'a (Late Roman Warlords) natomiast wyszła w serii Oxford Classical Monographs (s. 195); opracowanie T. Sticklera (Aëtius) zaś to tom 54 serii Vestigia (s. 197). Przykładów tego typu potknięć można by podać jeszcze wiele. Inny problem to cytowanie publikacji rosyjskiej w transkrypcji. Chodzi o książkę E.P. Glušanina (Voennaja znat'rannej Vizantii, Barnaul 1991) - s. 32, przyp. 39; s. 60, przyp. 51; s. 61, przyp. 53; s. 71, przyp. 105; s. 72, przyp. 106 i 108; s. 74, przyp. 112; s. 192. Wydaje się, że lepiej byłoby zacytować przedmiotowe opracowanie w języku oryginału: E.П. Глушанин, Военная знать ранней Византии, Барнаул 1991. Podobnie ma się rzecz z pracą zbiorową Military Archaeology. Weaponry and Warfare in the Historical and Social Perspective, Materials of the International Conference, 2-5 September 1998, ed. G.V. Vilinbakhov - V.M. Masson, St. Petersburg 1998 (s. 36, przyp. 53 i s. 196). Pozycja ta bowiem ma tytuł zarówno w języku angielskim, jak i rosyjskim. Ten ostatni brzmi Военная археология: Оружие и военное дело в исторической и соииальной перспективе, Материаль Международной конференции, Санкт-Петербург, 2-5 сентября 1998, редколлегия: Г.В. Вилинбахов - В.М. Массон (ответственные редакторы), Санкт-Петербург 1998. Należało raczej zacytować obie wersje tytułu, co byłoby zgodne z opisem bibliograficznym, który zamieszczono w rzeczonej zbiorówce.

Mimo wskazanych wyżej niedociągnięć należy bardzo pozytywnie ocenić rozprawę pana Łukasza Pigońskiego. Trzeba też raz jeszcze podkreślić, że książka ta powstała na bazie pracy magisterskiej, co wskazuje na ogromny potencjał jej autora. Pracę tę można z powodzeniem uznać za znaczący wkład do polskiej bibliografii przedmiotu. Ł. Pigoński wykazał się w niej zdolnością do wnikliwego wnioskowania i krytycznego korzystania z prac innych badaczy. To zaś niewątpliwie dobrze rokuje na przyszłość. Wypada zatem pogratulować autorowi i życzyć mu, aby nie wytracił schwytanego w intelektualne żagle wiatru. 